\title{
Protein Unc-13 Homolog D
}

National Cancer Institute

\section{Source}

National Cancer Institute. Protein Unc-13 Homolog D. NCI Thesaurus. Code C114617.

Protein unc-13 homolog D (1090 aa, 123 kDa) is encoded by the human UNC13D gene.

This protein is involved in maturation and secretion of cytolytic granules. 